\title{
The public's response to the obesity epidemic in Australia: weight concerns and weight control practices of men and women
}

\author{
Anna Timperio, David Cameron-Smith, Catherine Burns and David Crawford* \\ School of Health Sciences, Deakin University, Burwood, Victoria 3125, Australia
}

Submitted 9 November 1999: Accepted 3 March 2000

\begin{abstract}
Objective: To assess weight perceptions, weight concerns and weight control behaviours and related beliefs in a representative sample of adults.

Design: Cross-sectional postal survey.

Setting: The survey was conducted between October and December 1997 in the state of Victoria, Australia.

Subjects: A total of 2500 subjects were selected at random from the Australian electoral roll; 900 provided usable responses.

Results: At the time of the survey, $2.7 \%$ of respondents were trying to gain weight, $26.6 \%$ were trying to avoid gaining weight, $22.9 \%$ were trying to lose weight and $47.9 \%$ were not doing anything for their weight. Men (47.2\%) were less likely than women $(55.3 \%)$ to be attempting any form of weight control. Watching the type of food eaten (95.6\%), reducing dietary fat intake (87.3\%) and engaging in physical activity or exercise (84.4\%) were the most common weight control strategies used. Potentially harmful strategies, such as self-induced vomiting and smoking, were used by relatively few respondents. Many adults believed that vigorous activity (26.8\%) and total omission of fat from the diet (35.3\%) are necessary in order to lose weight. Conclusions: Attempts at weight control are common in the community. However, many men, including men who are already overweight, appear to be unconcerned about their weight. Obesity prevention initiatives should attempt to influence individuals' weight-related beliefs and behaviours, as well as seeking to change policies and environments to better support weight control.
\end{abstract}

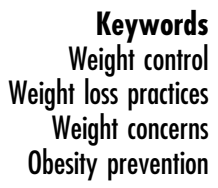

Keywords

Whight contiol Weight concerns Obesity prevention
Throughout the world, obesity arguably poses one of the major public health nutrition problems of the immediate future. For example, data from 1995 show that 18\% of Australian adults are obese ${ }^{1}$, compared with only $9 \%$ in $1980^{2}$. Similar trends in obesity are apparent in the USA, where $20 \%$ of men and $25 \%$ of women are now obese, in the UK, where prevalence has more than doubled since 1980 to $16 \%$, and in many other industrialized countries ${ }^{3}$. Disturbingly, high rates of obesity have also been observed in several developing countries ${ }^{3}$. From a public health perspective, obesity is of concern because of its association with increased risk of several debilitating, chronic and life-threatening health conditions ${ }^{4}$, as well as significant economic costs 5 .

Traditionally, public health efforts to reduce obesity have focused on encouraging weight loss among the overweight. However, given that the long-term outcome of clinical treatment of obesity is poor, and the cost of treatment is high ${ }^{6,7}$, health authorities have recently recognized the importance of preventing weight gain as the essential first step toward reducing the prevalence of obesity. Population-wide prevention of obesity has been described by the World Health Organization (WHO) as an approach which is more likely to be cost-effective and have a greater impact on long-term control of body weight than strategies aimed at those already overweight or obese $^{3}$. Australia is the first country to develop a national obesity prevention strategy ${ }^{8}$. The goal of that strategy is 'to prevent further weight gain in adults and eventually reduce the proportion of the adult population that is overweight or obese; and to ensure the healthy growth of children' ${ }^{, 8}$.

While leading the world in its policy response to the obesity epidemic, Australia has few data regarding public concerns about obesity, nor their responses to it ${ }^{9}$. However, information such as this is important for the planning and implementation of effective initiatives. Data from North America and Europe show that many men and women are concerned about obesity. Population surveys conducted in the USA ${ }^{10-13}$, Canada ${ }^{14}$, the Netherlands ${ }^{15}$ and in several other European Union countries ${ }^{16}$ reveal that $15-35 \%$ of adults will be attempting to reduce their weight at any time, with women more likely than men to be taking action. Although there is a growing body of data on the prevalence of weight loss attempts, little is known about the specific nature, frequency or duration of weight 
loss strategies ${ }^{17}$. In addition, relatively few studies have considered other aspects of weight control ${ }^{17}$, with only limited details of weight maintenance behaviours available $^{11,12}$. In Australia, data such as these are only available in one population survey ${ }^{18}$.

Given the current emphasis on promoting populationwide weight control as a means of preventing obesity, it is important to gain a better understanding of weight-related concerns, and weight loss and weight maintenance practices. This is especially important since the prevalence of obesity is increasing at a time when dieting and other weight control behaviour is widespread. The aims of this study are to assess weight perceptions, weight concerns and weight control behaviours and related beliefs in a representative sample of adults.

\section{Methods}

\section{Subjects}

Formal ethical clearance for this study was granted by the Deakin University Ethics Committee. A self-administered questionnaire about physical activity, dietary habits and weight control concerns and beliefs was developed for this study (described below). During its development, the questionnaire underwent pilot testing for clarity and comprehensibility with a group of 15 adults. A few minor amendments were made as a result of this testing. The questionnaire was distributed by post to a random sample of 2500 adults selected from the electoral rolls of the state of Victoria, Australia (registration compulsory for all Australian citizens over 18 years), in October 1997. Nonrespondents were mailed a reminder postcard after 2 weeks, a replacement questionnaire after a further 2 weeks and a final reminder postcard 2 weeks later. Of the 2500 questionnaires distributed, 973 usable, completed questionnaires were returned, and 160 were confirmed as addressed to persons unable to be contacted. Taking noncontact into account, a response rate of $42 \%$ was achieved (973/2340).

\section{Measures}

\section{Demographic information}

Details of sex, age, country of birth, marital status, education and occupation were requested.

\section{Body mass index}

Self-reported height and weight were used to calculate body mass index (BMI = weight in kilograms/height in metres squared). Although height tends to be slightly overestimated and weight underestimated, self-reported height and weight have been used extensively in population-based health research to estimate BMI. This is because they correlate highly with measured values and are a practical method of obtaining BMI data in large population surveys ${ }^{19}$. Subjects were classified into one of four BMI categories according to criteria recommended for

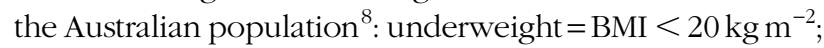
acceptable weight $=$ BMI 20 -25 ; overweight $=$ BMI $>25-$ $30 ;$ obese $=\mathrm{BMI}>30 \mathrm{~kg} \mathrm{~m}^{-2}$. The categories of 'overweight' and 'obese' are the same as those recommended by $\mathrm{WHO}^{3}$.

\section{Perceptions of weight}

Respondents were asked the following questions about their current and past weight: 'Do you have a weight problem at the moment?'; 'Have you had a weight problem in the past?'; 'Has your weight stayed the same over the last 6 months?'; 'Do you find it hard to keep your weight at its' current level?'; and 'Are you the kind of person who never puts on weight no matter what you do?'. Respondents were also asked 'How concerned are you about your current weight?', to which the following response categories were provided: not at all concerned; not very concerned; quite concerned; very concerned. They were then asked 'Do you consider your weight as harmful to your health?', to which the following response categories were provided: not at all harmful; not very harmful; quite harmful; very harmful.

\section{Perceptions of ideal weight}

Respondents were asked, 'Do you consider your current weight to be your ideal weight?' If not, they were asked, 'Ideally, how much would you like to weigh at the moment? (without clothes or shoes)'. Ideal weight was combined with self-reported height to calculate 'ideal BMI'.

\section{Weight control behaviour}

Respondents were asked to nominate which of the following categories best describes them: actively doing things to try to gain weight; actively doing things to try to avoid gaining weight; actively doing things to try to lose weight; not doing anything in particular for their weight. Those who reported trying to avoid weight gain or lose weight were asked whether they had lost weight, gained weight, or neither lost nor gained weight in their current attempt, and if so, how much they had lost or gained.

\section{Weight control strategies}

Respondents who were trying to lose weight or avoid gaining weight were asked to nominate the weight control strategies they were currently using from a list of 14 strategies (listed in Table 2). Those taking diuretics or fluid pills, slimming tablets or pills, laxatives, or meal replacement drinks, or who were skipping meals (fasting) or counting calories, were asked how long they had been using that particular strategy.

\section{Beliefs about weight loss methods and the benefits of weight loss}

Respondents were presented with a series of seven statements about weight loss methods (listed in Table 3). 
They were also presented with the following statements: 'Overweight people would feel more optimistic if they lost weight'; 'Overweight people would feel more attractive if they lost weight'; 'Overweight people would be less selfconscious if they lost weight'; 'The health of overweight people would improve if they were able to lose some weight'; and 'Overweight people would feel more energetic if they lost weight'. The following response categories were provided for all statements: strongly disagree; disagree; unsure/neutral; agree; strongly agree. For analysis, 'strongly disagree' and 'disagree' were combined, as were 'strongly agree' and 'agree'.

\section{Statistical analyses}

All pregnant women and subjects for whom data about pregnancy, sex, height, weight or weight control behaviour were missing $(n=73)$ were excluded from analyses. The analyses reported here are based on 900 adults $(382$ males and 518 females). In some analyses a small number of cases are missing for individual variables. All analyses were performed using SPSS version $8.0^{20}$ at a 0.05 (twotailed) significance level. Pearson's chi-square was used to compare BMI, perceptions of current and ideal weight, weight control behaviour and beliefs about weight loss methods and benefits by sex, and by BMI within sex. Weight control strategies were compared by sex within weight control behaviour (trying to lose weight and trying to avoid weight gain). Descriptive statistics were used to describe weight gains and losses, and the duration of specific weight control strategies. Paired and independent $t$-tests were used to compare current and ideal weight and $\mathrm{BMI}$, and reported weight losses.

\section{Results}

\section{Sample characteristics}

Most respondents (57.9\%) were women and the mean age of respondents was 44.7 ( \pm 16.5$)$ years. Most were born in Australia (78.2\%) and were currently married (61.7\%). Just under one-third (29.8\%) had not completed high school, $36.5 \%$ had completed high school, a technical or trade school certificate, or an apprenticeship, and 33.6\% had a university or tertiary qualification. A third of respondents (32.7\%) were not employed, $11.2 \%$ were employed in managerial or administrative positions and $14.6 \%$ were professionals. Compared to census data ${ }^{21,22}$, women, adults aged between 50 and 59 years, Australian-born women, married adults and those employed in high status occupations were slightly overrepresented in this sample.

\section{Body mass index}

The average height of male and female respondents was $177.6( \pm 7.3) \mathrm{cm}$ and $163.0( \pm 7.0) \mathrm{cm}$, respectively. Mean weight was $80.2( \pm 12.7) \mathrm{kg}$ among men and $65.4( \pm 14.0)$ $\mathrm{kg}$ among women. Mean BMI was $25.4( \pm 3.6) \mathrm{kg} \mathrm{m}^{-2}$ among men and $24.6( \pm 5.2) \mathrm{kg} \mathrm{m}^{-2}$ among women $(t=$ 2.6, $P<0.01)$. Very few men $(4.2 \%)$ were classified as underweight, $47.4 \%$ were within the healthy weight range, $38.2 \%$ were overweight and 10.2\% were obese. Among women, $15.8 \%$ were underweight, $45.8 \%$ were an acceptable weight, 23.9\% were overweight and 14.5\% were obese. Men were more likely than women to be overweight $(P<0.001)$. Compared with data from the National Health Survey ${ }^{23}$, a nationally representative study also using self-reported height and weight, the BMI distribution of the sample is representative of the Victorian population.

\section{Perceptions of weight}

Women were more likely than men to report they had a current weight problem, have had a weight problem in the past, have been unable to maintain a stable weight in the past 6 months, and find it hard to avoid gaining weight (Table 1). Women were also more likely to be concerned about their current weight and were more likely to report that not gaining weight in the next year is very important to them personally. Men were more likely than women to be confident that they could avoid gaining weight, and more likely to believe they are the type of person who never gains weight.

Men and women who were not overweight or obese $\left(\mathrm{BMI} \leqslant 25 \mathrm{~kg} \mathrm{~m}^{-2}\right)$ were more likely to report they had maintained a constant weight over the past 6 months and to describe themselves as the sort of person who never gains weight, compared with those men and women who were overweight or obese (Table 1). Overweight or obese men and women were more likely to report they currently have a weight problem, have had a weight problem in the past, and find it difficult to maintain their weight. They were also more likely to be concerned about their weight and perceive their current weight as harmful.

\section{Perceptions of ideal weight}

Overall, 38.0\% of respondents considered their current weight to be their ideal weight, with men more likely than women to hold this view (Table 1). Although one in five overweight or obese men considered their current weight to be their ideal weight, very few overweight or obese women described their weight as ideal. The mean weight men considered to be their ideal was $76.5( \pm 9.8) \mathrm{kg}$, or $3.7 \mathrm{~kg}$ less than their mean current weight $(P<0.001)$. The mean weight women considered to be their ideal weight was 58.9 ( \pm 2.9$) \mathrm{kg}$, or $6.3 \mathrm{~kg}$ less than their current weight $(P<0.001)$. On average, the mean ideal weight of overweight or obese men $(81.8 \pm 9.0 \mathrm{~kg})$ was $10 \mathrm{~kg}$ heavier than that of other men $(71.6 \pm 7.7 \mathrm{~kg}, P<0.001)$, and the mean ideal weight of overweight or obese women $(64.1 \pm 7.8 \mathrm{~kg})$ was approximately $10 \mathrm{~kg}$ heavier than that of other women $(55.7 \pm 6.5 \mathrm{~kg}, P<0.001)$.

Based on their ideal weight, the mean ideal BMI of respondents was $23.1( \pm 2.9) \mathrm{kg} \mathrm{m}^{-2}$. The mean ideal BMI 
Table 1 Perceptions and concerns regarding weight, and weight control behaviour, by sex and BMl $\left(\mathrm{kg} \mathrm{m}^{-2}\right)$ within sex

\begin{tabular}{|c|c|c|c|c|c|c|}
\hline \multirow[b]{2}{*}{ Perceptions } & \multicolumn{3}{|c|}{ Men (\%) } & \multicolumn{3}{|c|}{ Women (\%) } \\
\hline & $\begin{array}{c}\mathrm{BMI} \leqslant 25 \\
(n=188)\end{array}$ & $\begin{array}{c}\mathrm{BMI}>25 \\
(n=181)\end{array}$ & $\begin{array}{c}\text { Total } \\
(n=369)\end{array}$ & $\begin{array}{c}\mathrm{BMI} \leqslant 25 \\
(n=305)\end{array}$ & $\begin{array}{c}\mathrm{BMI}>25 \\
(n=183)\end{array}$ & $\begin{array}{c}\text { Total } \\
(n=488)\end{array}$ \\
\hline \multicolumn{7}{|l|}{ Current and past weight ${ }^{1}$} \\
\hline Current weight problem & $7.4^{\star *}$ & $58.6^{\star *}$ & $32.5 \ddagger$ & $19.7^{\star \star}$ & $83.1^{\star *}$ & $43.4 \ddagger$ \\
\hline Weight problem in past & $21.8^{\star \star}$ & $50.3^{\star \star}$ & $35.8 \ddagger$ & $33.1^{\star \star}$ & $76.5^{\star \star}$ & $49.4 \ddagger$ \\
\hline Weight remained stable over past 6 months & $87.8^{\star *}$ & $71.8^{\star *}$ & $79.9 \ddagger$ & $70.2^{*}$ & $58.5^{\star}$ & $65.8 \ddagger$ \\
\hline Difficult to maintain current weight & $6.4^{\star *}$ & $27.1^{\star \star}$ & $16.5 \ddagger$ & $16.1^{\star \star}$ & $43.7^{\star \star}$ & $26.4 \ddagger$ \\
\hline Type of person who never gains weight & $45.7^{\star *}$ & $13.3^{\star *}$ & $29.8 \ddagger$ & $28.2^{\star \star}$ & $5.5^{\star \star}$ & $19.7 \ddagger$ \\
\hline Consider current weight 'ideal' & $62.2^{\star \star}$ & $22.1^{\star \star}$ & $42.5 \dagger$ & $52.8^{\star \star}$ & $6.0^{* *}$ & $35.2 \dagger$ \\
\hline \multicolumn{7}{|l|}{ Level of concern about current weight } \\
\hline Not at all concerned & 53.7 & 23.2 & 38.8 & 35.7 & 4.9 & 24.2 \\
\hline Not very concerned & 41.5 & 38.1 & 39.8 & 44.9 & 29.0 & 38.9 \\
\hline Quite concerned & 4.3 & 30.4 & 17.1 & 15.7 & 37.7 & 24.0 \\
\hline Very concerned & $0.5^{\star *}$ & $8.3^{\star *}$ & $4.3 \ddagger$ & $3.6^{\star *}$ & $28.4^{\star *}$ & $12.9 \ddagger$ \\
\hline \multicolumn{7}{|l|}{ Weight harmful to health } \\
\hline Not at all harmful & 69.1 & 23.2 & 46.6 & 63.6 & 14.8 & 45.3 \\
\hline Not very harmful & 23.4 & 44.8 & 33.9 & 30.2 & 30.1 & 30.1 \\
\hline Quite harmful & 5.3 & 23.8 & 14.4 & 5.2 & 36.1 & 16.8 \\
\hline Very harmful & $2.1^{\star \star}$ & $8.3^{\star \star}$ & 5.1 & $1.0^{\star \star}$ & $19.1^{\star \star}$ & 7.8 \\
\hline \multicolumn{7}{|l|}{ Weight control behaviour } \\
\hline Trying to gain weight & 5.9 & 0.6 & 3.3 & 3.3 & 0.0 & 2.0 \\
\hline Trying to avoid gaining weight & 19.1 & 32.6 & 25.7 & 23.9 & 31.1 & 26.6 \\
\hline Trying to lose weight & 9.0 & 27.6 & 18.2 & 17.7 & 41.0 & 26.4 \\
\hline Doing nothing to control weight & $66.0^{\star \star}$ & $39.2^{\star \star}$ & $52.8 \dagger$ & $55.1^{\star \star}$ & $27.9^{\star \star}$ & $44.9 \dagger$ \\
\hline
\end{tabular}

${ }^{1}$ Proportion (\%) who responded 'yes'.

${ }^{\star} P<0.01,{ }^{\star \star} P<0.001$ : Pearson chi-square by BMI.

$\dagger P<0.05, \ddagger P \leqslant 0.001$ : Pearson chi-square by sex.

of women $\left(22.2 \pm 2.9 \mathrm{~kg} \mathrm{~m}^{-2}\right)$ was significantly less than that of men $\left(24.2 \pm 2.4 \mathrm{~kg} \mathrm{~m}^{-2}, P<0.001\right)$. The mean ideal BMI of overweight and obese men $\left(25.8 \pm 2.0 \mathrm{~kg} \mathrm{~m}^{-2}\right)$ was greater than that of other men $\left(22.7 \pm 1.6 \mathrm{~kg} \mathrm{~m}^{-2}, P<\right.$ $0.001)$, and the mean ideal BMI of overweight or obese women $\left(24.5 \pm 2.8 \mathrm{~kg} \mathrm{~m}^{-2}\right)$ was greater than that of other women $\left(20.7 \pm 1.8 \mathrm{~kg} \mathrm{~m}^{-2}, P<0.001\right)$.

\section{Weight control behaviour}

Women were more likely than men to be attempting weight loss, while men were less likely than women to be attempting any weight control (Table 1). Men and women who were overweight or obese were more likely than other men and women to have been trying to avoid gaining weight or to reduce their weight. However, it is noteworthy that two in five men and one in four women with a BMI $>25 \mathrm{~kg} \mathrm{~m}^{-2}$ were not doing anything in particular for their weight.

Watching the type of food eaten (95.6\%), reducing dietary fat intake (87.3\%), engaging in physical activity or exercise (84.4\%), avoiding sugar (65.1\%), reducing the overall amount of food eaten (63.2\%) and avoiding alcohol (52.0\%) were the most common weight control strategies used by men and women attempting weight control (Table 2). Few respondents used potentially harmful strategies such as smoking (4.6\%), counting calories or kilojoules (4.4\%), self-induced vomiting (1.4\%) and taking meal replacement drinks (2.4\%), diuretics or fluid pills (2.2\%), laxatives (1.5\%) and other slimming tablets or pills (1.2\%). On average, counting calories or kilojoules was used for $5.3( \pm 8.7)$ years (range: 2 weeks to 30 years), diuretics for 4.8 ( \pm 6.90$)$ years (range: 1 week to 20 years), laxatives for 4.9 ( \pm 5.9 ) years (range: 2 weeks to 15 years) and other types of slimming tablets used for $2.4( \pm 4.3$ ) years (range: 2 weeks to 10 years). Meal replacement drinks were used for an average duration of 23.6 ( \pm 53.8 ) weeks (range: 1 week to 3 years). One in $10(11.7 \%)$ respondents reported fasting or skipping meals as a weight control strategy, and reported doing so for an average of $4.1( \pm 4.8)$ years (ranging from 2 weeks to 20 years).

Women were more likely than men to report reducing their fat intake, avoiding sugar and avoiding alcohol as weight control strategies (Table 2). While men and women who were trying to avoid weight gain used similar strategies, among those trying to lose weight, women were more likely than men to report reducing their fat intake, avoiding sugar and avoiding alcohol.

\section{Weight change}

Among respondents who were trying to avoid gaining weight, $58.7 \%$ reported their weight had neither increased nor decreased, a third (32.0\%) reported they had lost weight and $9.3 \%$ reported gaining weight during their current attempt. Reported outcomes of attempts to maintain weight did not vary according to sex or weight 
Table 2 Prevalence of weight control strategies used to avoid gaining weight and to lose weight, by sex and weight control behaviour within sex

\begin{tabular}{|c|c|c|c|c|c|c|}
\hline \multirow[b]{2}{*}{ Weight control strategies } & \multicolumn{3}{|c|}{ Men (\%) } & \multicolumn{3}{|c|}{ Women (\%) } \\
\hline & $\begin{array}{l}\text { Avoid weight gain } \\
\qquad(n=90)\end{array}$ & $\begin{array}{l}\text { Lose weight } \\
\qquad(n=60)\end{array}$ & $\begin{array}{c}\text { Total } \\
(n=150)\end{array}$ & $\begin{array}{l}\text { Avoid weight gain } \\
\qquad(n=129)\end{array}$ & $\begin{array}{l}\text { Lose weight } \\
\qquad(n=131)\end{array}$ & $\begin{array}{c}\text { Total } \\
(n=260)\end{array}$ \\
\hline Reduce overall amount of food eaten & 57.8 & 70.0 & 62.7 & 58.9 & 67.9 & 63.5 \\
\hline Watching the type of food eaten & 97.8 & 91.7 & 95.3 & 94.6 & 96.9 & 95.8 \\
\hline Reducing the amount of fat in the diet & 84.4 & 76.7 & $81.3 \ddagger$ & 89.1 & 92.4 & $90.8 \ddagger$ \\
\hline Avoiding sugar & 56.7 & 55.0 & $56.0 \ddagger$ & 68.2 & 72.5 & $70.4 \ddagger$ \\
\hline Avoiding alcohol & 43.4 & 45.0 & $44.0 \dagger$ & 52.7 & 60.3 & $56.5 \dagger$ \\
\hline Doing physical activity or exercise & 85.6 & 88.3 & 86.7 & 76.7 & 89.3 & 83.1 \\
\hline Making self vomit after eating & 0.0 & 0.0 & 0.0 & 1.6 & 3.8 & 2.7 \\
\hline Fasting or skipping meals & 11.1 & 11.7 & 11.3 & 9.3 & 14.5 & 11.9 \\
\hline Counting calories or kilojoules & 3.3 & 3.3 & 3.3 & $0.8^{\star \star}$ & $9.2^{\star \star}$ & 5.0 \\
\hline Smoking for weight control & 5.6 & 3.3 & 4.7 & 3.1 & 6.1 & 4.6 \\
\hline Taking diuretics or fluid pills & 3.3 & 0.0 & 2.0 & 1.6 & 3.1 & 2.3 \\
\hline Taking laxatives & 0.0 & 0.0 & 0.0 & 2.3 & 2.3 & 2.3 \\
\hline Taking other slimming tablets or pills & 1.1 & 0.0 & 0.7 & 1.6 & 1.5 & 1.5 \\
\hline Taking meal replacement drinks & 0.0 & 1.7 & 0.7 & $0.8^{*}$ & $6.1^{*}$ & 3.5 \\
\hline Other & 26.7 & 30.0 & 28.0 & $16.3^{*}$ & $26.7^{\star}$ & 21.5 \\
\hline
\end{tabular}

${ }^{\star} P<0.05,{ }^{* \star} P<0.01$ : Pearson chi-square test of significance by weight control behaviour.

$\dagger P<0.05, \ddagger P<0.01$ : Pearson chi-square test of significance by sex.

status. Among those attempting weight loss, most (57.7\%) reported having lost weight, $38.5 \%$ reported having neither lost nor gained weight and 3.8\% reported gaining weight during their current attempt. Reported outcomes for attempts to lose weight did not vary according to sex or weight status. The mean reported weight loss of those who had lost weight was $5.5( \pm 6.5) \mathrm{kg}$.

\section{Beliefs about weight loss methods}

Men were more likely than women to believe that walking is not an effective way to lose weight, that vigorous activity is necessary for weight loss and that dieting would take the pleasure out of meals (Table 3). Overweight or obese men and women were more likely than other men and women to hold the perception that exercising to lose weight is

Table 3 Beliefs about methods of weight loss, compared by sex and BMI $\left(\mathrm{kg} \mathrm{m}^{-2}\right)$ within sex

\begin{tabular}{|c|c|c|c|c|c|c|c|}
\hline \multirow[b]{2}{*}{ Belief statements } & \multirow[b]{2}{*}{ Response } & \multicolumn{3}{|c|}{ Men (\%) } & \multicolumn{3}{|c|}{ Women (\%) } \\
\hline & & $\begin{array}{l}\mathrm{BMI} \leqslant 25 \\
(n=191)\end{array}$ & $\begin{array}{l}\mathrm{BMI}>25 \\
(n=175)\end{array}$ & $\begin{array}{c}\text { Total } \\
(n=366)\end{array}$ & $\begin{array}{l}\mathrm{BMI} \leqslant 25 \\
(n=305)\end{array}$ & $\begin{array}{l}\mathrm{BMI}>25 \\
(n=190)\end{array}$ & $\begin{array}{c}\text { Total } \\
(n=495)\end{array}$ \\
\hline \multirow[t]{3}{*}{ Walking is not an effective way to lose weight } & Disagree & 69 & 70 & 69 & 79 & 79 & 79 \\
\hline & Neutral & 16 & 12 & 14 & 10 & 8 & 9 \\
\hline & Agree & 16 & 18 & $17 \dagger$ & 11 & 13 & $12 \dagger$ \\
\hline \multirow{3}{*}{$\begin{array}{l}\text { In order to lose weight, people need to perform } \\
\text { vigorous physical activity that makes them } \\
\text { puff and pant }\end{array}$} & Disagree & 53 & 58 & 55 & 67 & 63 & 66 \\
\hline & Neutral & 18 & 12 & 15 & 10 & 10 & 10 \\
\hline & Agree & 29 & 30 & $30 \dagger$ & 23 & 28 & $25 \dagger$ \\
\hline \multirow[t]{3}{*}{ Exercising to lose weight is boring hard work } & Disagree & 57 & 54 & 56 & 62 & 43 & 55 \\
\hline & Neutral & 19 & 10 & 15 & 11 & 11 & 11 \\
\hline & Agree & $24^{*}$ & $35^{*}$ & 30 & $28^{\star *}$ & $46^{* *}$ & 35 \\
\hline \multirow{3}{*}{$\begin{array}{l}\text { Unless you try and cut out fats completely, it } \\
\text { will not help lose weight }\end{array}$} & Disagree & 47 & 39 & 43 & 53 & 42 & 49 \\
\hline & Neutral & 20 & 18 & 19 & 17 & 17 & 17 \\
\hline & Agree & 33 & 42 & 37 & $30^{*}$ & $41^{*}$ & 34 \\
\hline \multirow{3}{*}{$\begin{array}{l}\text { Eating less food is not an effective way to } \\
\text { lose weight }\end{array}$} & Disagree & 28 & 34 & 31 & 35 & 32 & 34 \\
\hline & Neutral & 10 & 11 & 11 & 7 & 7 & 7 \\
\hline & Agree & 62 & 55 & 59 & 58 & 61 & 59 \\
\hline \multirow[t]{3}{*}{ Dieting would take the pleasure out of meals } & Disagree & 45 & 30 & 38 & 54 & 49 & 52 \\
\hline & Neutral & 23 & 18 & 21 & 14 & 17 & 15 \\
\hline & Agree & $33^{\star \star}$ & $51^{\star \star}$ & $42 \ddagger$ & 32 & 34 & $33 \ddagger$ \\
\hline \multirow{3}{*}{$\begin{array}{l}\text { Losing weight could be expensive when } \\
\text { everything is taken into account }\end{array}$} & Disagree & 53 & 50 & 51 & 54 & 45 & 51 \\
\hline & Neutral & 22 & 22 & 22 & 18 & 17 & 17 \\
\hline & Agree & 26 & 29 & 27 & 28 & 38 & 32 \\
\hline
\end{tabular}

${ }^{*} P<0.05,{ }^{* *} P \leqslant 0.001$ : Pearson chi-square test of significance by BMI.

$\dagger P<0.01, \ddagger P<0.001$ : Pearson chi-square test of significance by sex. 
boring hard work. Overweight or obese men were also more likely than other men to believe that dieting takes the pleasure out of meals, and overweight or obese women were more likely than other women to believe it is necessary to completely avoid dietary fat in order to lose weight.

\section{Beliefs about benefits of weight loss}

Most respondents felt that losing weight would improve health (91.7\%), energy levels (90.5\%), optimism (73.1\%) and attractiveness $(72.4 \%)$ among those overweight, and that overweight people would feel less self-conscious (72.0\%) if they reduced their weight. Men (76.1\%) were more likely than women $(70.9 \%)$ to believe that losing weight would increase optimism $(P<0.05)$. Overweight or obese women $(79.8 \%)$ were more likely than other women $(66.9 \%)$ to believe that losing weight would increase feelings of attractiveness $(P<0.01)$.

\section{Discussion}

This study provides a valuable insight into obesity prevention priorities among Australian men and women. It shows that weight-related issues are important to a significant portion of the population. Many adults report they find it difficult to maintain their weight, many perceive they have a weight problem, are concerned about their weight and see their weight as harmful, with almost one in two actively trying to lose weight or to avoid weight gain. While we did not specifically pose questions about perceptions of the need for action to counter the obesity epidemic, these findings do suggest that future public health initiatives that endeavour to further promote and support healthy weight control are likely to be welcomed by many men and women.

Although it is encouraging that many respondents were taking action to control their weight, the views and practices of overweight men are a matter of concern. One in five believed their weight to be ideal, were unconcerned about it and did not see their weight as harmful, and a further $40 \%$ expressed only mild concern. These findings are consistent with earlier research which shows many overweight men have inaccurate weight perceptions ${ }^{15,24-26}$, and may partially explain why $40 \%$ were not taking steps to reduce or maintain weight. Even though most overweight men in this study recognize the range of health and other benefits associated with weight loss, they are unlikely to be influenced by this while they see their own weight as ideal. It is therefore important that greater efforts are made to educate men as to what constitutes a healthy weight.

Compared with overweight men, the overweight women in this study were much more likely to express concern about their weight and to be taking action for their weight. In fact, on almost all of our measures, women were far more conscious of weight-related issues than were men. While these findings are not new $^{27}$, it is important to consider them in the context of obesity prevention efforts. We might ask whether, in attempting to prevent weight gain, we have unwittingly caused women to put their health at risk by encouraging unhealthy weight preoccupation? However, there is little evidence for this in the existing literature ${ }^{17}$. In addition, the weight control strategies most commonly used by respondents in this study were those recommended by health authorities ${ }^{28}$, although a few used unhealthy practices and had done so for a considerable length of time. Given this, future prevention initiatives should stress healthy weight control practices, and encourage those women who are not overweight to focus on maintaining weight, rather than attempting to further reduce it.

Australia's obesity prevention strategy focuses particularly on bringing about policy- and environmental-level changes to increase opportunities for physical activity and to make healthy food choices easier ${ }^{8}$. However, data presented here suggest that it will also be important to focus on influencing individuals' behaviours and beliefs. In promoting weight control, our findings indicate, for example, a need to highlight the benefits of moderateintensity physical activity that is easy, social, fun and sustainable. Many respondents erroneously believed that vigorous physical activity is essential for weight loss, and consider exercising to lose weight to be boring, hard work. These perceptions may act as barriers not only to participation in physical activity, but also to attempting weight control. Similarly, obesity prevention messages should focus on providing information about the types of dietary changes that would best aid long-term weight control, since many respondents held the view that losing weight involves restricting food choice and makes meals less enjoyable.

Despite some negative beliefs about weight control, it is noteworthy that a significant number of men and women who reported a former weight problem were not overweight at the time of the survey and did not consider their current weight to be a problem. While recognizing the methodological limitations with such retrospective, selfreported data ${ }^{29}$, they do suggest that significant numbers of men and women may have been successful in losing weight, at least as they judge success themselves. However, to properly understand the public's response to the obesity epidemic, and their ability to successfully control weight, much more detailed information is required. In particular, it will be important to continue to gather data on the nature, frequency and duration of specific weight control practices, and to prospectively examine the relationship between weight control behaviours and weight change ${ }^{17}$. Information such as this is important to the development and monitoring of obesity prevention initiatives.

Potential limitations of this study relate to the modest response rate and the self-report nature of the data. Other 
recently published studies of population-based surveys of this kind have reported similar response rates ${ }^{30}$. In this study, the sociodemographic profile of our sample was generally representative of the Victorian population ${ }^{21,22}$, the prevalence of weight control was similar to recent Australian data ${ }^{18}$, and the weight control strategies commonly nominated were similar to those reported previously ${ }^{10-12,14,18}$. Although the prevalence of being overweight and obese was similar to national data based on self-reported height and weight ${ }^{23}$, levels of overweight and obesity may be underestimated in this study due to underestimation of weight and/or overestimation of height ${ }^{31}$. In addition, the findings reported here may be influenced by social desirability biases, where respondents may be less likely to admit to trying to control their weight and may not report using potentially harmful weight control strategies. While it is necessary to treat the findings reported here with some caution, they do provide an important insight into the public's weight concerns and weight control practices.

\section{Conclusions}

This study has shown that attempts at weight control are common in the community. However, many men, including men who are already overweight, appear to be quite unconcerned about their weight, possibly placing themselves at risk of further weight gain. The majority of those attempting weight control use strategies that are recommended by health authorities, however a small number use potentially harmful strategies and may be at risk from long-term use. Given that many men and women hold unrealistic perceptions of their weight and negative beliefs about weight control, obesity prevention initiatives should attempt to influence individuals' weight-related beliefs and behaviours, as well as focusing on changing policies and environments to better support weight control.

\section{Acknowledgements}

This research was supported by a grant from the Australian Research Council and Deakin University. Anna Timperio is a recipient of a Deakin University Postgraduate Research Award. David Crawford was supported by a Public Health Fellowship from the National Health and Medical Research Council and is currently supported by a National Heart Foundation Nutrition Research Fellowship.

\section{References}

1 Australian Bureau of Statistics. National Nutrition Survey: Selected Highlights, Australia 1995. Catalogue No. 4802.0. Canberra: Australian Government Publishing Service, 1997.

2 National Heart Foundation of Australia. Risk Factor Prevalence Study. Report No. 1. Canberra: National Heart Foundation of Australia, 1981.
3 World Health Organization. Obesity: Preventing and Managing the Global Epidemic. Report of the WHO Consultation of Obesity. Geneva: World Health Organization, 1997.

4 Pi-Sunyer FX. Medical hazards of obesity. Ann. Intern. Med. 1993; 119: 655-60.

5 Wolf AM, Colditz GA. Current estimates of the economic cost of obesity in the United States. Obes. Res. 1998; 6: 97-175.

6 Brownell KD, Rodin J. The dieting maelstrom: is it possible and advisable to lose weight? Am. Psychol. 1994; 49: 78191.

7 Gill TP. Key issues in the prevention of obesity. Br. Med. Bull. 1997; 53: 359-88.

8 National Health and Medical Research Council. Acting on Australia's Weight: a Strategy for the Prevention of Overweight and Obesity. Canberra: Australian Government Publishing Service, 1997.

9 Crawford D, Owen N. The behavioural epidemiology of weight control. Aust. J. Public Health 1994; 18: 143-8.

10 Levy AS, Heaton AW. Weight control practices of US adults trying to lose weight. Ann. Intern. Med. 1993; 119: 661-6.

11 Neumark-Sztainer D, Sherwood NE, French SA, Jeffery RW. Weight control behaviors among adult men and women: cause for concern? Obes. Res. 1999; 7: 179-88.

12 Serdula MK, Mokdad AH, Williamson DF, Galuska DA, Mendlein JM, Heath GW. Prevalence of attempting weight loss and strategies for controlling weight. JAMA 1999; 282 $1353-8$

13 Williamson DF, Serdula MK, Anda RF, Levy A, Byers T. Weight loss attempts in adults: goals, duration, and rate of weight loss. Am. J. Public Health 1992; 82: 1251-7.

14 Green KL, Cameron R, Polivy J, et al. Weight dissatisfaction and weight loss attempts among Canadian adults. Can. Med. Assoc. J. 1997; 157: S17-25.

15 Blokstra A, Burns CM, Seidell JC. Perception of weight status and dieting behaviour in Dutch men and women. Int. J. Obes. 1999; 23: 7-17.

16 Lappalainen R, Tuomisto MT, Giachetti I, D’Amicis A, Paquet $\mathrm{S}$. Recent body-weight changes and weight loss practices in the European Union. Public Health Nutr. 1999; 2: 135-41.

17 French SA, Jeffery RW. Consequences of dieting to lose weight. Effects on physical and mental health. Health Psychol. 1994; 13: 195-212.

18 Crawford D, Owen N, Broom D, Worcester M, Oliver G. Weight-control practices of adults in a rural community. Aust. NZ J. Public Health 1998; 22: 73-9.

19 Waters AM. Assessment of Self-reported Height and Weight and their Use in the Determination of Body Mass Index. Canberra: Australian Institute of Health and Welfare, 1993.

20 SPSS Inc. SPSS 8.0 for Windows. Release 8.0. Chicago: SPSS Inc., 1997.

21 Australian Bureau of Statistics. Census of Population and Housing: Selected Social and Housing Characteristics for Statistical Local Areas, Victoria 1996. Catalogue No. 2015.2. Canberra: Australian Government Publishing Service, 1996.

22 Australian Bureau of Statistics. Labour Force, Victoria 1996. Catalogue No. 2602.2. Canberra: Australian Government Publishing Service, 1996.

23 Australian Bureau of Statistics. National Health Survey: Summary Results, Australian States and Territories. Catalogue No. 4368.0. Canberra: Australian Government Publishing Service, 1997.

24 Craig PL, Caterson ID. Weight and perceptions of body image in women and men in a Sydney sample. Community Health Stud. 1990; 14: 373-83.

25 Crawford D, Campbell K. Lay definitions of ideal weight and overweight. Int. J. Obes. 1999; 23: 738-45.

26 Tiggeman M, Winefield HR, Winefield AH, Goldney RD. Gender differences in psychological correlates of bodyweight in young adults. Psychol. Health 1994; 9: 345-51. 
27 Brownell K. Dieting and the search for the perfect body: where physiology and culture collide. Behav. Ther. 1991; 22: $1-12$.

28 NIH Technology Assessment Conference Panel. Methods for voluntary weight loss and control. Ann. Intern. Med. 1992; 116: 942-9.

29 Bartlett SJ, Faith MS, Fontaine KR, Cheskin LJ, Allison DB. Is the prevalence of successful weight loss and maintenance higher in the general community than the research clinic. Obes. Res. 1999; 7: 407-17.

30 Cox DN, Anderson AS, Lean MEJ, Mela DJ. UK consumer attitudes, beliefs and barriers to increasing fruit and vegetable consumption. Public Health Nutr. 1998; 1: 61-8.

31 Australian Bureau of Statistics. How Australians Measure Up. Catalogue No. 4359.0. Canberra: Australian Government Publishing Service, 1995. 